\title{
The Association between Helicobacter Pylori Infection and Hyperemesis Gravidarum
}

\author{
Osama Gamal Mohammad Elshazly," MB BCh., Mahmoud Abd-Eltawab Sultan² MD., Mohammad Salah \\ Eldin Hassanein ${ }^{2}$ MD., Attia Mohammad Attia ${ }^{2}$ MD. and Abd-Elaleem Abd-Elaleem Elgendy ${ }^{3}$ MD.
}

\author{
* Corresponding Author: \\ Elshazly, Osama Gamal \\ doctorcheva@yahoo.com
}

Received for publication January 24, 2020; Accepted May 12, 2020, Published online May 13, 2020.

Copyright 2020 The Authors published by Al-Azhar University, Faculty of Medicine, Cairo, Egypt. All rights reserved. This an openaccess article distributed under the legal terms, where it is permissible to download and share the work provided it is properly cited. The work cannot be changed in any way or used commercially.

doi: $10.21608 /$ aimj.2020.22069.1054

${ }^{1}$ Obstetrics and Gynecology Department, Ministry of Health Hospitals.

${ }^{2}$ Obstetrics and Gynecology Department, Faculty of Medicine, Al-Azhar University Cairo, Egypt.

${ }^{3}$ Clinical pathology Department, Faculty of Medicine, Al-Azhar University Cairo, Egypt.

\begin{abstract}
Background: Hyperemesis gravidarum is the severe form of nausea and vomiting of pregnancy. The reported incidence of Hyperemesis gravidarum is about $0.5-2.0 \%$. For the diagnosis of hyperemesis gravidarum there must be presence of three or more vomiting episodes during the day, weight loss of over 5\% and ketonuria. Studies have recently suggested that there is an association between emesis gravidarum and hyperemesis gravidarum with Helicobacter pylori infection. Serologically positive $H$. pylori infection has been demonstrated in hyperemesis patients.

Aim of the work: To detect if there is association between hyperemesis gravidarum and infection with helicobacter pylori.

Patients and methods: The study included 200 women that were classified into two groups. Group (1) 100 women with hyperemesis gravidarum and group (2) 100 women with usual antenatal care. Serum $\mathrm{H}$. pylori titre was measured for detection of seropositivity incidence in both groups.

Results: Regarding H. pylori $\operatorname{IgG}$ titre, there was significant difference between study group and control group.

Conclusion: This study concluded that there is significant correlation between Helicobacter pylori infection and occurrence of emesis gravidarum.
\end{abstract}

Keywords: Helicobacter Pylori; Interleukin; Virlence Factors Toxin.

Disclosure: The authors have no financial interest to declare in relation to the content of this article. The Article Processing Charge was paid for by the authors.

Authorship: All authors have a substantial contribution to the article.

\section{INTRODUCTION}

Nausea and vomiting during pregnancy, which is also known as 'morning sickness', affects between $70-80 \%$ of all pregnancies in the first trimester. Usually, it starts between 4 and 8 weeks of gestation, however the symptoms might continue till the 16 th -18 th week. It is generally a mild condition and self-limited. A small number of pregnant women have a more acute sequalae, with the most severe form known as hyperemesis gravidarum. ${ }^{1}$

In almost $1-10 \%$ of pregnancies, symptoms may continue till 20-22 weeks. ${ }^{2}$

Hyperemesis gravidarum (HG) is characterized by persistent nausea and vomiting accompanied by ketosis and loss of weight $(>5 \%$ of the weight before pregnancy). It may cause hypovolemia, electrolytes disturbance and acid-base imbalance, nutritional deficiencies, and even - in severe cases death. Severe cases with hyperemesis require hospitalization in $0.3-2 \%$ of pregnancies. ${ }^{3}$
Prevalence of hyperemesis gravidarum varies from 0.3 to $1.5 \%$ of all live births.

The exact etiology of hyperemesis gravidarum is not well known and is probably multifactorial in which psychological factors, disturbance of gastrointestinal motility, hormonal changes, infections, immunological, metabolic and anatomical factors appear to intervene. ${ }^{5}$

It is the most common cause of hospitalization in the first half of pregnancy and second only after preterm labor for pregnancy overall. It can be associated with serious maternal morbidity such as Wernicke's encephalopathy and fetal morbidity such as intrauterine growth retardation, and in severe cases maternal and fetal death may happen. ${ }^{4}$

The Helicobacter pylori (H. pylori) is considered as an important cause of gastritis in human beings and as an essential factor in the pathogenesis of peptic ulcer. Many findings suggest that Helicobacter 
pylori is also involved in the pathogenesis of cancer and lymphoma of the stomach. ${ }^{6}$

In developing countries, $70 \%$ to $90 \%$ of the population is infected by the bacteria, while in industrialized countries the prevalence is smaller, ranging between $25 \%$ and $50 \% .{ }^{4}$

Many methods of Helicobacter pylori testing exist. Noninvasive tests for Helicobacter pylori infection include the blood antibody test, the stool antigen test, or with the carbon urea breath test (in which the patient drinks $14 \mathrm{C}$ or $13 \mathrm{C}$ labelled urea, then the bacterium metabolizes the labelled urea producing labelled $\mathrm{CO} 2$ that can be detected in the breath of the patient). The other method for Helicobacter pylori infection detection is endoscopic biopsy check with a rapid urease test, histological examination, and microbial culture. ${ }^{7}$

In essence, serology samples the whole stomach whereas biopsy only samples a small portion, and the inflammatory process may be patchy, so serologic analysis is considered more sensitive than diagnostic methods involving biopsy. The development of Helicobacter pylori-specific fluorescent serum antibody test helps for easy and suitable screening for $H$. pylori infection and because of its simple, cheap and non invasive testing, it becones possible to detect Helicobacter pylori infection in pregnant women. ${ }^{8}$

\section{PATIENTS AND METHODS}

The study was carried out in Gynecology and Obstetric Department, Bab-Elshaaria Hospital, Faculty of Medicine, Al-Azhar University, Cairo. This study included 200 pregnant women at 6-18 weeks of gestation. They were recruited from Outpatient Clinic. They were divided into 2 groups: Group A (study group) that included 100 pregnant women with emesis gravidarum and group B (control group) that included 100 healthy pregnant women. The ages ranged between 16-38 years old at 6 to 18 weeks of gestation, medically free by history taking and by physical examination especially GIT and thyroid diseases and with single healthy viable intrauterine pregnancy. Patients with clinical thyroid dysfunction or hyperthyroidism with pregnancy, medical disorders especially that cause vomiting as GIT diseases or past history of ulcer, multiple pregnancy and gestational trophoplastic diseases were excluded. All cases were subjected to the following:

full history taking, clinical examination, transabdominal or transvaginal pelvic sonogram, laboratory investigations including complete blood count, serum electrolytes, liver and kidney function tests, urine analysis, thyroid functions and H.pylori IgG testing by ELISA.

\section{Statistical methodology:}

Data were statistically described in terms of range, mean, standard deviation $( \pm \mathrm{SD})$, median, frequencies (number of cases) and relative frequencies (percentages) when appropriate. Comparison of quantitative variables between different groups in the present study was done using Student $\mathrm{t}$ test for independent samples. For comparing categorical data, Chi square $\left(\chi^{2}\right)$ test was performed. Yates correction was used instead when the expected frequency is less than 5. A probability value ( $p$ value) less than 0.05 was considered statistically significant. All statistical calculations were done using computer programs Microsoft Excel version 7 (Microsoft Corporation, NY, USA) and SPSS (Statistical Package for the Social Science; SPSS Inc., Chicago, IL, USA) statistical program.

\section{RESULTS}

\begin{tabular}{|c|c|c|c|c|c|c|c|c|c|}
\hline & & & ans & & Mean & \pm & S. D & t. test & p. value \\
\hline \multirow{2}{*}{$\begin{array}{l}\text { IgG } \\
\text { antibod } \\
\text { y titers }\end{array}$} & Group A & 1 & - & 100 & 47.02 & \pm & 36.51 & \multirow{2}{*}{28.325} & \multirow{2}{*}{$0.001 *$} \\
\hline & Group B & 0.9 & - & 62.7 & 24.97 & \pm & 19.58 & & \\
\hline
\end{tabular}

Table 1: Helicobacter pylori IgG antibody titers in emesis gravidarum and control groups

Comparison between group $\mathrm{A}$ and group $\mathrm{B}$ regarding IgG antibody titers showed highly

significant statistical difference where $\operatorname{IgG}$ titers was higher in group $\mathrm{A}$.

\begin{tabular}{||l|c|ccc|ccc|c|l||}
\hline \multicolumn{2}{|c|}{} & \multicolumn{3}{|c|}{ Range } & Mean & \pm & S. D & t. test & p. value \\
\hline $\begin{array}{l}\text { IgG antibody } \\
\text { titers } \\
\text { Primigravida }\end{array}$ & Group A & 2.8 & - & 100 & 50.34 & \pm & 47.12 & 7.324 & $0.009 *$ \\
\cline { 2 - 9 } & Group B & 0.9 & - & 48.6 & 24.71 & \pm & 20.07 & 7.32 & \\
\hline
\end{tabular}

Table 2: Helicobacter pylori IgG antibody titer of primigravida in emesis gravidarum (A) and control (B) groups. 
significant statistical difference where $\operatorname{IgG}$ titers in primigravida was higher in group A.

\begin{tabular}{||c|c|ccc|ccc|c|l||}
\hline \multicolumn{2}{|c|}{} & \multicolumn{3}{|c|}{ Range } & Mean & \pm & S. D & t. test & p. value \\
\hline $\begin{array}{c}\text { IgG antibody } \\
\text { titers } \\
\text { Multigravida }\end{array}$ & Group A & 1 & - & 86.8 & 44.81 & \pm & 27.51 & \multirow{2}{*}{23.107} & $0.001 *$ \\
\cline { 2 - 8 } & Group B & 3.8 & - & 62.7 & 25.07 & \pm & 19.53 & & \\
\hline \hline
\end{tabular}

Table 3: Helicobacter pylori IgG antibody titer of multigravida in emesis gravidarum (A) and control (B) groups

Comparison between multigravida in group A and group B regarding IgG antibody titers showed significant statistical difference where $\operatorname{IgG}$ titer was higher in group $\mathrm{A}$.

\begin{tabular}{|c|c|c|c|c|c|}
\hline \multicolumn{3}{|c|}{ H.P Igg } & Group A & Group B & Total \\
\hline \multirow{2}{*}{\multicolumn{2}{|c|}{ +ve }} & $\mathrm{N}$ & 68 & 60 & 128 \\
\hline & & $\%$ & $68.0 \%$ & $60.0 \%$ & $64.0 \%$ \\
\hline \multirow{2}{*}{\multicolumn{2}{|c|}{-ve }} & $\mathrm{N}$ & 32 & 40 & 72 \\
\hline & & $\%$ & $32.0 \%$ & $40.0 \%$ & $36.0 \%$ \\
\hline \multirow{2}{*}{\multicolumn{2}{|c|}{ Total }} & $\mathrm{N}$ & 100 & 100 & 200 \\
\hline & & $\%$ & $100.0 \%$ & $100.0 \%$ & $100.0 \%$ \\
\hline \multirow{2}{*}{ Chi-square } & $x^{2}$ & \multicolumn{4}{|c|}{1.389} \\
\hline & P-value & \multicolumn{4}{|c|}{0.239} \\
\hline
\end{tabular}

Table 4: Helicobacter pylori IgG seropositivity in emesis gravidarum and control groups.

Comparison between group A and group B regarding IgG Seropositivity showed no significant statistical difference.

\section{DISCUSSION}

Studies as Wu et al. ${ }^{15}$, Hayakawa et al. ${ }^{25}$ and Karaca et al. $^{26}$ suggested that chronic Helicobacter pylori infection may play a role in hyperemesis gravidarum. H.pylori seropositivity was present in up to $60 \%$ of pregnant women compared with $50 \%$ in the general population. Helicobacter pylori infection was found in cases of persistent vomiting in pregnancy who were not responding to supportive treatment. However, endoscopic diagnosis should not be performed unless initial non-invasive tests are negative. ${ }^{27}$

In our study, 200 pregnant females from 6 to 18 weeks were subjected to detailed history, physical examination, ultrasonography and Helicobacter pylori IgG assay by ELISA. 100 pregnant females were complaining of emesis gravidarum group (A) and 100 pregnant females were not complaining of emesis gravidarum group (B).We compared data collected from the two groups as regard maternal age, gestational age, parity, $\operatorname{IgG}$ antibody titre and IgG antibody seorpositivity. In this study, we aimed to find the relation between $\mathrm{H}$. pylori and emesis gravidarum.

As regard IgG titers. we found that there was highly significant statistical difference between group(A) and group (B) as the mean value of $\operatorname{IgG}$ titers in group (A) was (47.02) but in group (B) the mean was (24.97). This result agrees with many studies done by Frigo et al. ${ }^{7}$, Kocak et al. ${ }^{17}$ and Jamal et al. ${ }^{14}$ Frigo et al. ${ }^{7}$ found that the mean value of H.pylori IgG antibody titer in emesis group was 74.2 and in control group was $24.3(\mathrm{p}<0.01)$. Kocak et al. $^{17}$ found that the mean value of H.pylori IgG antibody titer in emesis group was 73.8 and in control group was $25.8(\mathrm{p}<0.01)$. Jamal et al. 14 found that the mean $\operatorname{IgG}$ antibody titer in emesis group was 25 compared to 10.5 in control group $(\mathrm{P}<0.05)$.

Possible explanations for the tendency of H. pylori to cause nausea and vomiting may be abnormal gastric emptying, reduced gastrointestinal motility in pregnancy and hypersensitivity to gastric or duodenal distention. ${ }^{9}$ Murakami et al. ${ }^{19}$ reported that eradication of Helicobacter pylori accelerate gastric emptying and postprandial gastric sensation while Rhee et al. ${ }^{20}$ could not show these effects. However, since nausea and vomiting in pregnancy also exist in the absence of $\mathrm{H}$. pylori colonization, this suggests that the presence of the bacteria is not obligatory for the induction of nausea and vomiting in pregnancy. 9

Regarding IgG antibody titers, we found that there was highly significant statistical difference between primigravida in group (A) and group (B) where IgG titers of primigravida in group (A) was 50.34 but in group $(\mathrm{B})$ the mean was $24.71(\mathrm{P}$ value $=0.009)$. Comparing between multigravida in group $\mathrm{A}$ and group B regarding IgG antibody titers. There was highly significant statistical difference between multigravida in group (A) and group (B) where the 
mean value of IgG titers of multigravida in group (A) was (44.81) but in group (B) the mean was (25.07) ( $\mathrm{P}$ value $=0.001)$. This result agrees with the previously mentioned results the mean of $\mathrm{IgG}$ antibody titers in group (A) is more than that in group (B). In addition, we compared between both groups as regard seroposotivity. We found that 68 cases (68\%) in group (A) were seropositive and 32 cases $(32 \%)$ were seronegative while in group (B) 60 cases $(60 \%)$ were seropositive and 40 cases $(40 \%)$ were seronegative. Our results suggest that there was strong association between helicobacter pylori and emesis gravidarum. Our study revealed higher $\mathrm{H}$. pylori seropositivity in pregnant women with emesis gravidarum. This result is similar to previous studies reporting a seropositive rate of more than $68 \%$ H.pylori infection in patients with emesis gravidarum. A case control study was done by Mai et al. 18 on Egyptian hyperemesis patients and healthy pregnant ladies. It showed a significant association between Helicobacter pylori infection and hyperemesis gravidarum, where $84.4 \%$ were $\mathrm{H}$. pylori positive and $15.6 \%$ were negative.

Although a high rate of seropositivity for H. pylori in patients with emesis gravidarum was revealed, Khayati et al. ${ }^{12}$ found no correlation between the onset and duration of symptoms and seropositivity in the emesis gravidarum group. The findings done by Khayati et al. ${ }^{12}$ may reflect either the existence of underlying mechanisms other than $\mathrm{H}$. pylori in the exacerbation of emesis gravidarum, or the complex nature of the $H$. pylori infection related symptoms. This is consistent with findings done by Erdem et al. $^{21}$ and Nakajima et al. ${ }^{22}$ whose research failed to reveal a correlation between seropositivity for helicobacter pylori in emesis gravidarum and the severity of clinical symptoms. Future studies may elucidate the association of emesis gravidarum and $\mathrm{H}$. pylori.

In our study, seropositivity was $68 \%$. Although this result was not found by other studies, high prevalence of $\mathrm{H}$. pylori has been reported among women with emesis gravidarum in other studies. Kosunen et al. ${ }^{23}$ reported that detection of $\mathrm{H}$. pylori IgG by whole-blood or serum-based serologic tests, may not reflect current active infection because antibodies are positive several months or even years after infection. Moreover, since antibody titer against $\mathrm{H}$. pylori may be elevated for several months after successful eradication, this may increase the false- positives rates. However, the serology test is still widely used for initial diagnosis before eradication therapy. ${ }^{9}$

Furthermore women participated in our study were not given $\mathrm{H}$. pylori eradication regimens during pregnancy. In addition, we found seropositivity was high in both groups as group (A) seropositivity was $(68 \%)$ and in group (B) was (60\%). This may be due to lack of demographic data such as socioeconomic status, which may be a risk factor for Helicobacter pylori infection. ${ }^{8}$ However, most of the study participants who presented to our clinic in both groups (patient and control) belonged to the low socioeconomic class. Therefore, this factor may not affect the result of this study, and the rate of $\mathrm{H}$. pylori was high in both groups. Moreover, it is well known that $\mathrm{H}$. pylori infection is one of the most common human infections in the world which may reach $90 \%$ in developing countries and the majority of infected subjects remain asymptomatic. 24

Golberg et al. ${ }^{24}$ reported that some studies showed no significant association between Helicobacter pylori infection and emesis gravidarum. This may be because these studies have small sample sizes, which may also have precluded discovery of an association. Another limitation is that the study relies on patient recall of symptoms during pregnancy, which may cause self-reporting bias. They suggested that the ideal study would be a randomized placebocontrolled trial examining symptomatic improvement in $\mathrm{H}$. pylori infected hyperemesis gravidarum patients after $\mathrm{H}$. pylori eradication and performing the study using larger sample sizes. An explanation for the discrepancy between these studies and our study may be due to any of the multiple risk factors as "age, race, socioeconomic status, blood grouping, parity, cigarette smoking and changes in the environmental factor", that can affect the prevalence $\mathrm{H}$. pylori infection during pregnancy, as well as difference in methodology.

\section{CONCLUSION}

Our study results gave powerful correlation between $\mathrm{H}$. pylori and emesis gravidarum, which matche with the results of many previous studies. Taking into consideration the complex nature of etiological factors of emesis gravidarum and Helicobacter pyloriinfection.

\section{REFERENCES}

1. Nasr AA, Aboulfoutouh I, Nada A, et al. Is there an association between Helicobacter pylori infection and hyperemesis gravidarum among Egyptian women? Evidence Based Women's Health Journal. 2012; 2:100-103.

2. Bailit JL. Hyperemesis gravidarum: Epidemiologic findings from a large cohort. $\mathrm{Am}$ J Obstet Gynecol. 2005;193(3 Pt 1):811-4.

3. Mansour GM and Nashaat EH. Role of Helicobacter pylori in the pathogenesis of hyperemesis gravidarum. Arch Gynecol Obstet. 2011; 284:843-847.

4. Nanbakhsh F, Mohaddesi H, Bahadory F, et al. Comparison of Helicobacter pylori infection between pregnant women with hyperemesis gravidarum and controls. World Applied Sciences Journal. 2013; 28 (12): 1918-1922. 
5. Guven MA, Ertas IE, Coskun A, et al. Serologic and stool antigen assay of Helicobacter pylori infection in hyperemesis gravidarum: Which test is useful during early pregnancy? Taiwanese Journal of Obstetrics \& Gynecology. 2011; 50:37e41.

6. Boltin D, Perets TT, Elheiga SA, et al. Helicobacter pylori infection amongst Arab women with hyperemesis gravidarum-a prospective, controlled study. International Journal of Infectious Diseases. 2014; 29 :292295.

7. Stenström B, Mendis A and Marshall B. Helicobacter pylori-The latest in diagnosis and treatment. Aust Fam Physician. 2008; 37 (8): 608-12.

8. Kazerooni T, Taallom $\mathrm{M}$ and Ghaderi AA. Helicobacter pylori seropositivity in patients with hyperemesis gravidarum. International Journal of Gynecology and Obstetrics. 2002; 79: 217-220.

9. Shirin H, Sadan O, Shevah O et al. Positive serology for Helicobacter pylori and vomiting in the pregnancy. Arch Gynecol Obestet. 2004; 270:10-14.

10. Loughlin MF, and Jenks PJ. Monotherapy with mastic does not eradicate Helicobacter pylori infection from mice. J Antimicrob Chemother. 2003; 51 (2): 367-71.

11. Aspholm M, Farzad O, Nordén J et al. SabA is the H.pylori hemagglutinin and is polymorphic in binding to sialylated Glycans. PLoS Pathog. 2006;2 (10):110-6.

12. Khayati S A , Sharami H, Ghanaei $\mathrm{F}$ et al. Helicobacter pylori aeropositivity and the incidence of hyperemesis gravidarum. Med Sci Monit. 2003 ; 9 (1): 12-5.

13. Davis M. Nausea and vomiting of pregnancy: An evidence-based review. J Perinat Neonatal Nurs. 2004; 4: 312- 28.

14. Jamal A, Pooransari P and Ansari R. Relation between Helicobacter pylori seropositivity and hyperemesis gravidarum. Acta Medica Iranica., 42. 2004; (5): 367-370.

15. Wu CY, Tseng J, Chou MN et al. Correlation between Helicobacter pylori infection and gasterointestinal symptoms in pregnancy. $A d v$ Ther. 2000; 17 (3): 152-158.

16. Broussard $\mathrm{CN}$ and Richter JE. Nausea and vomiting of pregnancy. Gastroenterol Clin
North Am. 1998; 27: 123-51.

17. Kocak I, Akcan Y, Ustun C et al. Helicobacter pylori seropositivity in patients with hyperemesis gravi- darum. Int $J$ Gynaecol Obstet. 1999; 66: 251-254.

18. Mai E, Abo Seada M, Shafik A, et al. Role of the Helicobacter pylori in the pathogenesis of hyperemesis gravidarum. MsC thesis, Ain Shams Faculty of Medicine, Department of Obstetrics and Gynecology. 2014.

19. Murakami K, Fujioka $T$, Shiota $\mathrm{K}$ et al. Influence of Helicobacter pylori infection and the effects of its eradication on gastric emptying in nonulcerative gastritis. Eur $J$ Gastroenterol Hepatol. 1995; 1: 93-97.

20. Rhee PL, Kim YH, Son HJ et al. Lack of association of Helicobacter pylori infection with gastric hypersensitivity or delayed gastric emptying in functional dyspepsia. $A m J$ Gastroenterol. 1999; 94: 3165- 3169.

21. Erdem A, Arslan M, Erdem M et al. Detection of Helicobacter pylori seropositivity in hyperemesis gravidarum and correlation with symptoms. Am J Perinatol. 2002; 19: 87-92.

22. Nakajima N, Hayakawa S, Suzuki M et al. H. pylori infection:a possible pathogenic factor of hyperemesis gravidarum? Proc Japan Assoc Immunol Reprod. 1998; 12: 87-88.

23. Kosunen TU, Seppala K, Sarna $\mathrm{S}$ et al. Diagnostic value of decreasing IgG, IgA and IgM antibody titers after eradication of $\mathrm{H}$. pylori. Lancet. 1992; 339: 893-895.

24. Golberg D, Szilagyi A and Graves L. Hyperemesis gravidarum and H.pylori infection:a systematic review. Obstet Gynecol. 2007; 110 (3): 695-703.

25. Hayakawa S, Nakajima N, Karasaki-Suzuki M et al. Frequent presence of Helicobacter pylori genome in the saliva of patients with hyperemesis gravidarum. Am J Perinatol. 2000;17:243-247.

26. Karaca C, Guler N, Yazar A et al. Is lower socio- economic status a risk factor for Helicobacter pylori infection in pregnant women with hyperemesis gravidarum? Turk $J$ Gastroenterol. 2004; 15: 86-89.

27. Loh KY, Sivalingam. Understanding hyperemesis gravidarum. Med $J$ Malaysia. 2005; 60 (3):394-9. 